\title{
COVID-19 Crisis and Resilience: Challenges for the Insurance Sector
}

\author{
Susanna Levantesi ${ }^{1}$ and Gabriella Piscopo ${ }^{2}$
}

\begin{abstract}
The main role of the insurance sector is the coverage of risks through pooling techniques. Against the payment of a premium, the insurance company compensates for unexpected losses, including catastrophic events and pandemics. However, differently from a catastrophic event, the COVID-19 pandemic has highlighted that the global impact on economic and financial activities is highly correlated. The insurance sector itself has been strongly affected both by the exponential growth of claims in the life and non-life sectors and by the negative impact on financial activities. Past experiences in pandemic risk management have been unsuccessful. This paper retraces the instruments issued following the past pandemics and tries to reflect on how the insurance sector can implement innovative solutions to support post-pandemic resilience.
\end{abstract}

JEL classification numbers: G22.

Keywords: COVID-19, Catastrophic risk, Insurance sector, Pandemic risk, Resilience solutions.

${ }^{1}$ Department of Statistics, Sapienza University of Rome.

${ }^{2}$ Department of Economics and Statistical Science, University of Naples Federico II.

Article Info: Received: February 10, 2021. Revised: February 24, 2021.

Published online: March 23, 2021. 


\section{Introduction}

COVID-19 pandemic is offering a challenge to the insurance sector to both support a proactive resilience of businesses and offer virus resilience solutions (Simpson, 2020). The insurance industry can help to manage risks during the future unexpected crises and pandemics (National Academies of Sciences, Engineering, and Medicine, 2016) and sustain the society in the economic recovery, addressing capitals to investments (Nature 583, 30, 2020) and lending practices (Hans and Maxwell, 2020). Despite the recent occurrence of pandemics or epidemics (e.g. A/H1N1, MERS, SARS 2003), the insurance industry was not better prepared to face the considerable business losses caused by COVID-19. Following the SARS 2003, underwriters usually introduced exclusions to future pandemics in the insurance policies, rather than really addressing the issue. Nevertheless, the role of the insurance industry should be to manage risks arising from the coverage of unforeseen events. People are showing a growing interest in purchasing insurance to coverage losses of the potential new waves of pandemics and they are willing to pay major insurance premium to face more confidently the resilience. This represents for insurers a great opportunity to be seized. To achieve this goal, it is important to estimate the potential risks affecting value chains, to plan insurance coverages, to support a more effective risk management and mitigation by businesses, to offer innovative insurance products tailored to the needs of enterprises. Already ten years ago, Rappuoli et al. (2010) observed that 2009 $\mathrm{A} / \mathrm{H} 1 \mathrm{~N} 1$ pandemic highlighted the weakness of the medical, political and business systems and suggested the necessity of building an insurance for pandemic risk. As a matter of fact, without the central help of the government, the insurance system alone cannot face the challenge and the economic impact of COVID-19 and policymakers has to incorporate this reflection into long-term programs to reboot the economy (Nature 581, 262, 2020).

The attention on how businesses can respond to broader societal problems (Bapuji et al., 2020) is fervent. In this regard, the insurance industry plays a key role in ensuring that people preserve the value of their assets during periods of crisis. In addition to assume a cushioning role on the negative impact deriving from extraordinary and unexpected events, the insurance industry can take on a wider role in creating economic opportunities and support the recovery and the resilience in the post crisis. It is well known that insurance sector has sustained significatively the economic growth (Haiss and Sümegi, 2008; Mirela et al., 2014) and invested premiums pooled together into longer-term projects such as infrastructure development, energy market (Hans and Maxwell, 2000) and other strategic sectors. However, this is a difficult moment also for the insurance sector, who is facing an increase in requests for reimbursement as well as suffering the consequences of isolation measures like all other sectors. In addition, insurance companies are traditional investors in equity and fixed income markets and face losses due to the instability of the financial market and the cut in interest rates that central banks are making to support economy (Kaserer and Klein, 2019). In this scenario insurance 
companies can take a double attitude: try to survive the crisis by relying on the resources accumulated as solvency capital and on experience in risk management, or take a proactive attitude and try to adapt the offer to new market needs. In this paper we retrace the experience of the past pandemics and try to reflect on how the insurance sector can implement innovative solutions to support post-pandemic resilience. The work is organized as follows. Section 2 offers an overview of the impact of COVID-19 on the current insurance coverage. Some strategies implemented to address the negative economic impact of the past pandemics are described in Section 3. In Section 4 we offer food for thought on the challenges that the insurance industry is facing. Final remarks are presented in Section 5.

\section{An overview of the impact of COVID-19 on insurance coverages}

Insurers are not been well prepared to deal with the considerable business losses caused by COVID-19, although pandemics or epidemics (e.g. A/H1N1, MERS and SARS 2003) have recently occurred. After SARS 2003, underwriters no longer faced the issues rising from pandemic events, and have frequently excluded benefit payments due to pandemics in the insurance policies. The same has occurred in the case of COVID-19, where a large number of insurance companies have introduced these exclusions in their insurance contracts, both to those in force and the new ones. Nevertheless, there has been strong social pressure pushing insurers to include insurance coverage for pandemic events such as COVID-19.

Concerning life insurance, a possible exclusion is when death occurs during a journey to a country considered dangerous by the government. This kind of exclusion, however, does not concern the cause of death. According to Shennan (2020), reinsurers are highly exposed to the pandemic risk of morbidity and mortality, while Winters (2020) states that COVID-19 has the same impact as an average natural catastrophe in one case in 200 years (worst case scenario). The new policies emission is jeopardized by concerns about the evolution of the pandemic and the life insurance sector is approaching difficult challenges such as managing changes in mortality rates and negative financial impacts affecting their products. Concerning health insurance, the situation is different: there are some contracts not covering medical expenses for COVID-19 and some others that have included the coverage of medical services relative to the pandemic. Anyhow, pandemic events lead individuals to review their health insurance needs. As during SARS 2003, there was a spike in sales of critical illness policies, similarly a widespread increase in health insurance sales following COVID-19 is likely. Thanks to the exclusion clauses for epidemics introduced after the outbreak of SARS in 2003, the impact on claims of damages will be relatively manageable (KPMG, 2020).

As regard to travel insurance, contracts enclose the coverage of medical expenses when individuals travel outside their country, and travel cancellation. In the case of the current outbreak, some in force travel insurance policies are covering medical treatments caused by COVID-19 during travel, while a lot of insurance companies 
have no longer issued new travel insurance policies. The Association of British Insurers has estimated a loss of GBP 275 million, the strongest ever faced (Ralph, 2020) as some travel insurance policies did not enforce an exclusion to pandemics. Looking at the Business Interruption (BI) policies, which refund an organization only in case of physical damage, it is likely to incur in hard controversies if the COVID-19 related claims are not covered. This affects how undertakings invest and operate in response to a shock and will be briefly discussed in the next section.

As previously stated, COVID-19 is significantly hitting the insurance sector, which must deal with a large number of claims with its own funds but preserving the solvency balance. The current pandemic effects on insurance business primarily involve pricing, underwriting and product development, claims management and financial management. Specifically, it is likely to have a premium increment for those lines of business recording growing claims. First of all, travel insurance, which is affected by a lot of travel cancellations and for which the Association of British Insurers (2020a) estimates 400,000 COVID-related claims. On the other hand, some other lines of business will probably experience a premium decrease. The risk perception and, thus, customers behavior have been changed by the pandemic and we can expect a rising demand for insurance coverage, but with different nature respect to the past. To getting closer to the customers' need, insurance companies will probably revise the policy formulation. The impressive moving to home working is increasing cyber risk exposure. This kind of working could get standing or constitute a large part of the work, giving scope for a sudden growth of the cyber insurance market.

In the auto and motor insurance, we have experienced a considerable decrease in the claim frequency during the lockdown and in the subsequent weeks due to the reduction on car traffic. Overall, most lines of business are expected to obtain a reduction in the claims volume, except for health insurance, where claims number will rise according to the COVID-19 spread.

The insurance sector is claimed to manage controversies and litigation related to the pandemic coverages. It will pay attention to deeply investigate frauds following the increase of fraudulent activity, as well as to the BI insurance coverage. BI policies in the US are objective of a fervid legislative debate due to COVID-19. While, British insurers do not cover losses from BI due to COVID-19 for the general exclusion from coverage of any diseases that have been declared to be notifiable diseases under relevant Commonwealth legislation.

With regards to the financial management, we underline that the COVID-19 propagation is increasing the financial market volatility and decreasing the bond yield, then affecting the insurers' gain and their own funds. Evaluating and predicting financial performances by including adequate scenarios in the analysis and updated information on the pandemic developments, is fundamental for insurers. They have also to revise the investment portfolio, dividend policy and variable remuneration in order to meet their obligations towards policyholders. The insurers' solvency capital is indeed affected by the increased number of claims, the growing financial markets volatility, interest rates changes and asset value reductions, 
requiring the use of risk mitigation strategies to minimize the adverse effects of the pandemic on their financial position. In this context, the disclosure of information is fundamental as stated by the European Securities and Markets Authority (ESMA, 2020), which released a public statement to support updating information reflecting the expected impact of the COVID-19 outbreak and the uncertainties in its evolution. The disclosure of information about the COVID-19 impact is also necessary for insurers and should relate to assumptions and scenario analysis for estimating the insurance liabilities by line of business, risk concentrations, claims management, and market, liquidity and counterparty risk.

The increasing uncertainty related to the pandemic may induce insurers to assess the level of their solvency capital, which must be sufficient to absorb potential losses allowing to continue the underwriting in the upcoming years. Insurance companies have to continue to hold the role of risk transfer, as stated by the European Insurance and Occupational Pensions Authority in the document "EIOPA statement on dividends distribution and variable remuneration policies in the context of COVID-19" (EIOPA, 2020). EIOPA drives insurers to undertake actions that preserve their own fund from the uncertainty arising from COVID-19, also paying attention to the impact on their solvency capital requirements. Indeed, the lower return on investments and the higher claims exposure may cause a drop of the insurers' own funds, thus bringing them to rectify the actuarial evaluations to measure the impact of COVID-19 on capital needs and perform stress tests of their financial position to check the ability to continue to meet the regulatory capital requirements. Based on the principle of prudence, EIOPA recommends that "at the current juncture (re)insurers temporarily suspend all discretionary dividend distributions and share buy backs aimed at remunerating shareholders" with the promise that this stopping will be reconsidered by continuously monitoring the materiality of the pandemic impact on economy and financial markets.

\section{Lesson from the past}

Flu pandemics have occurred during the past at increasing intervals. There were three pandemics in the last century: the Spanish Flu pandemic in 1918/19, the Asian Flu pandemic in 1957/58, and the Hong Kong Flu pandemic in 1968/69. The Spanish Flu caused death of the approximately 4 percent of the global population at that time.

For the insurance industry the effects of a pandemic would be strong: taking into account life and health insurance, the rise in mortality of the insured population implies higher claims expenses for term, whole life, endowment and other death benefits, while lower expenses in annuity lines . However, the strong impact is due to the financial negative impact on asset side of insurance companies' balance sheets. The joint impact of mortality and financial shocks on US life insurers is shown by Kirti et al. (2020) under different scenarios, included the hypothesis of mortality similar to that realized during the Spanish Flu. However, as the same Spanish pandemic teaches us, the impact on life expectancy is temporary and the 
jump mortality process can be adequate to project mortality in the future taking into account the effect of possible recurrent pandemics. Barro (2020) also shows that the 1918-20 pandemic was accompanied by substantial short-term declines in realized real returns on stocks and short-term government bonds. From this point of view, to mitigate the negative impact of the pandemic on the balance sheets of insurance companies, temporary measures are necessary such as the delay in the distribution of dividends or temporary ad hoc measures by the regulators who postpone the fulfillment of the capital adequacy requirement to cushion the shocks. Alongside these measures, appropriate financial and insurance instruments and government policies must be set up to overcome the crisis. In this paragraph, we review what tools have been prepared in the past to reflect on future opportunities to be implemented in the post COVID-19.

Following SARS 2003, the insurance sector began to reflect on how it could offer solutions to cover the pandemic risk. The first, rather unsuccessful, solution in terms of traditional insurance product issued to address the pure pandemic risk has been the PathogenRX, designed by Marsh LLC jointly with Munich Re in 2018. The fact that only one policy was sold is eloquent (Ratliff, 2020). Hartwing et al. (2020) examines the reasons of the thin market: from the demand side there is an underestimation of the risk, due to people's belief that the governments likely will intervene with economic aids in the case of pandemic. On the supply side, the awareness of potential extreme losses and an ever less remote probability of occurrence leads to offering uncompetitive prices and introducing coverage exclusions.

Another solution to manage pandemic risk was offered by the World Bank's Pandemic Emergency Financing Facility (PEF). Following the 2014 Ebola pandemic spread on some African countries, the World Bank decided to create a new type of catastrophe bond called pandemic bonds. The bond was issued in June 2017, as part of the Pandemic Financing Emergency Facility, to help Third World countries in the case of future epidemics. The issue was constituted by two tranches: class A with an annual coupon of $6.5 \%$ plus the Libor rate, with a risk of capital loss limited to a maximum of $16.67 \%$ related to a COVID-19 event, and class B, with annual interest of $11.1 \%$ plus Libor, but with the danger of losing the whole capital. The two tranches of bonds expire on July 15, 2020, but can be extended monthly for a maximum of another 12 months. As well as the $\$ 320 \mathrm{~m}$ raised by the bonds, another $\$ 105 \mathrm{~m}$ was raised in swaps. Unexpectedly, the PEF has been widely criticized even though it has paid out $\$ 195.8$ million to 64 of the world's lowest income countries affected by the COVID-19 pandemic. The weaknesses of the PEF have been identified in the parametric triggers used to determine if and when payouts would be made (they were only reached in April, when the emergency had been developing for more than two months) and in the excessively high returns if the bonds, not financially sustainable by the issuer.

From failures of past experiences, lessons can be learned for the management of the post COVID-19 phase and of future pandemics. If on the one hand the traditional insurance product cannot be successful as well as the experience of World Bank 
Fund, the only viable ways are outlined: that of the shared solution between insurance sector and governments (EIOPA) and that which sees an active collaboration between insurers and insureds based on the design of structured insurance product, risk management accessory services and sustainable investments as described in the next paragraph.

\section{Insurance COVID-19 Resilience Solutions}

The latest pandemic has shown completely new elements compared to the previous ones, presenting itself as a global event with highly correlated effects on most economic and financial activities. In light of what has happened, we are convinced that the market for traditional pandemic policies (like PathogenRX) cannot be widespread. While the demand for pandemic business policies may have a boost after the spread of COVID-19, because the perception of the economic and financial risk deriving from a pandemic has increased, the supply remains rather inelastic. In fact, it cannot deviate from excessively onerous pricing levels if we consider the calculation of a pure premium in terms of the product of the probability of occurrence of the rare event and the expected loss. In this regard, it should be noted that the latest events have changed both the estimate of the probability of occurrence and that of the expected loss. With regard to the first aspect, just think that EIOPA in determining the solvency capital requirements against pandemic risk considers a probability of occurrence of 1 every 200 years. The succession of the latest pandemics (SARS and COVID-19) has highlighted a much shorter period of time and it is reasonable to think that in the future pandemics will develop at ever closer dates due to the strong interrelation between economies throughout the world. As regards the second aspect, the estimate of the expected loss will necessarily have to be revised upwards to take into account the strong correlation of the negative impacts on the economic and financial sectors. Another motivation behind the insurability of the pandemic risk is the issue of potential external moral hazard caused by distorted incentives for public policy decisions (Richter et al., 2020).

If there is no room for development for a traditional market for pandemic policies, we think the pandemic risk cannot even be treated in the same way as the catastrophe risk. The proposal to issue pandemic bonds (Richter et al., 2020) similar to cat bonds does not seem feasible from a practical point of view: if the latter may be attractive to investors for diversification needs, the former would have highly correlated returns with the financial markets and only a philanthropic motivation (not economically justifiable) could push to buy them.

Therefore, the insurance companies are faced with a choice. There are two possibilities. Continue to exclude pandemic risk from coverage, as done following SARS; in this case they would find themselves well capitalized (EIOPA, 2020) but in fact simply because they have not chosen to offer coverage from the pandemic risk and the level of capitalization is sufficient to cushion only the shock that the pandemic has caused on the sector itself. The second opportunity would be to take up a new challenge and propose innovative products and solutions to support post- 
COVID resilience. The problem must be faced in its complexity: the insurance sector must draw up an articulated plan based on the issue of tailor made insurance products, management investment services and assistance services. From a practical point of view, the main challenges for the insurance sector are offered by the digitalization of the sector, the expansion of the cyber branch and the issue of innovative sustainable products.

\subsection{Digitalization}

As the pandemic globally spread, people's use of technology are changing and COVID-19 is stimulating the digital transformation of the economy. Also insurance sector has to design new ways of working and meeting their customers' needs remotely, preserving the safety of customers and worker.

For many companies, the pandemic has accelerated the process of modernization of the sector, investing in technology infrastructure, improving data capabilities, favouring digital underwriting and claims processes. The underwriting process can benefit from the use of new data sources and decision models. In this context, the insurance companies has to looking for solutions to efficiently share data among different business units and from connected devices and use them in algorithmbased approaches. As during the current crisis the low interest and negative financial impact on the asset side of insurers' balance sheet is inevitable, they has to find ways to improve the profitability of their underwriting and customized products can be offered at a lower price thanks to digitalization. The Artificial Intelligence can offer evident advantages: data algorithms can improve the underwriting process; machine learning techniques can be deepen to manage policies and identify the specific risk of each of them; AI-powers chatbots can remotely provide customer services; telematics into customers' cars can improve the underwriting process and claims. The insurance companies could start this process themselves or draw up collaboration agreements with insurtech companies.

\subsection{Cyber insurance}

The global cyber insurance market size in the post-COVID-19 phase is forecasted to grow from USD 7.8 billion in 2020 to USD 20.4 billion by 2025 (Global newswire, 2020), nearly tripling in three years. It is inevitable that post COVID-19 organizations will need to rethink their cyber risk management measures. The expansion of information technology in business, the spread of social networks, wireless technologies and cloud services to allow the smart working required by the spread of pandemic and government restrictive measure, has led to increased vulnerability to cyber risk. Many companies are starting to consider cyber security as a large business risk and require insurance coverage to ensure the continuity of financial operations in case of cyber branch. The losses that can result from cyberattacks are huge and the resulting insurance policies can be excessively expensive if not accompanied by risk management assistance services. Insurance companies must make available their skills in risk management and adequately train the 
workers of client companies. IT experts and engineers must support the work of actuaries to contain IT risks thanks to the implementation of correct working practices.

\subsection{Sustainable Underwriting policies}

The biggest challenge that the insurance sector is called to face lies in designing specific products to meet market demands in the post-COVID phase. The urgent needs concern coverage for business interruption and policies to cover expenses following job loss or illness. The funds deriving from the placement of ad hoc products could be invested in sustainable projects to support the resilience of the post-COVID economy, favoring the triggering of virtuous circles (Di Lorenzo et al., 2020). From a practical point of view, insurance could encourage the underwriting of business interruption policies for those companies that are investing in postCOVID resilience, with discount policies reserved for those who take concrete actions to reduce the expected losses resulting from future pandemics (investments in the safety of the workplace, staff training on containment measures for the development of viruses, smart working solutions). Parallel to the discount policy, the insurance could support the company in the effective risk assessment through accessory risk management services. Experience in risk management could allow insurance to perform the risk management more efficiently and cheaper than internal company risk management functions. To this aim, one important challenge would be improve the understanding and quantification of business interruption risks to correctly price policies and the discount scheme derived from mitigation measures implemented. Currently, in the literature and in practice no models consider the positive impact of mitigation measures on business interruption risk. Usually catastrophic models are used to model the losses derived from the pandemic, but the experience of COVID-19 has revealed that the impact on economic activities of the pandemic spread is different from those of extreme natural events. The business interruption losses caused by a pandemic capture are influenced also by the expected duration of interruptions, which may depend on the recovery capacities of the affected company as well as on restrictive political measures or government support to the economy. For example, the insurer could offer sophisticated risk management models able to capture governmental lock-down scenarios. Some insurers are collected also model the pandemic risk data emerged during the COVID-19 to offer precise back-test models.

Finally, a pandemic private fund could be created. As has been highlighted, the pandemic risk cannot be diversified by customer groups as it has a strongly correlated impact on many economic activities and on different geographical areas. A possible risk management strategy could derive from pooling over time: for this purpose, pandemic funds could be created, managed with the approach of private pension funds, with the calculation of a general average premium in a collective capitalized scheme. 
The premiums raised could be invested in sectors that have shown better performance during the pandemic such as technology and pharmaceuticals. In the event of a pandemic, the insured would be entitled to receive a coverage proportional to the amount accumulated by the investment of the premium paid during the years.

The proposed insurance solutions, made up of innovative products and above all additional risk management services, can proceed in parallel with the provisions of EIOPA (2020) who suggests a shared resilience solution comprises public and private sector participation, enabling a risk transfer between private companies, insurance industry, reinsurance industry or capital markets, national government and supranational entities.

\section{Final remarks}

In this paper we have discussed the key roles the insurance sector can play during the spread of a pandemic and how it can support the recovery and the resilience in the post crisis. In response to the issues posed by COVID-19, insurance industry should be more focused on pandemic risk management as an opportunity of growth. Recently, demand for insurance are growing due to the awareness driven by COVID-19 concerns. For insurance companies introducing opportune risk models to price the pandemic products becomes a strategic tool. Digitalization of the insurance chain is one of the key tasks to be pursued in order to improve the efficiency of the integrated insurance processes, going from underwriting to the sales to accessory risk management services. The modernization process can be started in collaboration with the Insurtech start-ups, that are developing their business based on the revolution of big data and artificial intelligence. Many solutions to support post-COVID resilience have been suggested in this paper: the insurance sector must draw up an articulated plan based on the issue of tailor made insurance products, management investment services and assistance services. From a practical point of view, the main challenges for the insurance sector are offered by the digitalization of the sector, the expansion of the cyber branch and the issue of innovative sustainable products.

As it stands, the insurance industry was not prepared to face the considerable business losses due to COVID-19 pandemics. As a matter of fact, without the central help of the government, the insurance system alone cannot face the challenge. They may not have charged the full cost arising from pandemic; however, for its risk transfer and management activities, they can strongly contribute to raising society and business from this moment of great crisis together with governments and entrepreneurs. 


\section{References}

[1] Association of British Insurers (2020a). COVID-19 - Travel insurers expect to make record payouts to customers. Retrieved March 24, 2020 from https://www.abi.org.uk/news/news-articles/2020/03/covid19-travel-insurersexpect-to-make-record-payouts-to-customers/

[2] Association of British Insurers (2020b). Statement on business insurance and Coronavirus. https://www.abi.org.uk/news/news-articles/2020/03/statementon-business-insurance-and-coronavirus/

[3] Bapuji, H., de Bakker, F.G.A., Brown, J.A., Higgins, C., Rehbein, K., and Spicer. A. (2020). Business and Society Research in Times of the Corona Crisis. Business \& Society, 59(6), 1067-1078

[4] Barro, R.J., Ursúa, J.F., Weng, J. (2020). The coronavirus and the Great Infuenza Pandemic: lessons from the "Spanish Flu" for the coronavirus's potential efects on mortality and economic activity. NBER Working Paper No. 26866, Cambridge, MA

[5] Di Lorenzo, E. and Sibillo, M. (2020). Economic Paradigms and Corporate Culture after the Great COVID-19 Pandemic: Towards a New Role of Welfare Organisations and Insurers. Sustainability, 12, 8163.

[6] European Insurance and Occupational Pensions Authority (2020). EIOPA statement on dividends distribution and variable remuneration policies in the context of COVID-19. Retrieved April 2, 2020 from https://www.eiopa.europa.eu/content/eiopa-statement-dividendsdistribution-and-variable-remuneration-policies-context-covid-19_en

[7] European Securities and Markets Authority (2020). Implications of the COVID-19 outbreak on the half-yearly financial reports. ESMA 32-63-972.

Retrieved May 20, 2020 from https://www.esma.europa.eu/sites/default/files/library/esma32-63972_public_statement_on_halfyearly_financial_reports_in_relation_to_covid-19.pdf

[8] Global Newswire (2020). Global Cyber insurance Market report 2020. Research and market, October 27, 2020.

Available at newswire: https://www.reportlinker.com/p05977659/?utm_source=GNW

[9] Haiss, P., and Sümegi, K. (2008). The relationship between insurance and economic growth in Europe: A theoretical and empirical analysis. Empirica, 35 (4), pp. 405-431.

[10] Hans, P., and Maxwell, N.R. (2020). COVID-19: Insurance Coverage for the Energy and Manufacturing Industries.

National Underwriter perspective. Retrieved March, 12, 2020 from https://andersonkill.com//Custom/PublicationPDF/PublicationID_1833_COV ID-19-Insurance-Coverage-for-the-Energy-and-ManufacturingIndustries_Hans_Maxwell.pdf 
[11] Hartwing, R., Niehaus, G. and Qiu, J. (2020). Insurance for economic losses caused by pandemics. The Geneva Risk and Insurance Review, 45, pp. 134170

[12] Kaserer, C., and Klein, C. (2019). Systemic Risk in Financial Markets: How Systemically Important Are Insurers? Journal Risk and Insurance, 86, 729-759.

[13] Kirti, D. and Shin, M.Y. (2020). Impact of Covid-19 on insurers. International Monetary Fund Research, May 18, 2020

[14] KPMG (2020). Do insurers have COVID-19 covered? https://home.kpmg/xx/en/home/insights/2020/03/do-insurers-have-covid-19covered.html

[15] Mirela, C., Nicu, M. and Silviu, C. (2014).

The Relationship between Insurance and Economic Growth in Romania Compared to the Main Results in Europe - A Theoretical and Empirical Analysis. Procedia Economics and Finance, 8(12), pp. 226-235

[16] National Academies of Sciences, Engineering, and Medicine (2016). Global Health Risk Framework: Pandemic Financing: Workshop Summary. Washington, DC: The National Academies Press. https://doi.org/10.17226/21855

[17] Ralph, O. (2020). UK travel insurers set for year of payout pain. Financial Times. Retrieved March 24, 2020, from https://www.ft.com/content/a81bbcba-6d2a-11ea-89df-41bea055720b

[18] Rappuoli, R., Medini, D., Siena, E., Budroni, S., Dormitzer, P.R. and Del Giudice, G. (2010). Building an insurance against modern pandemics. Current Opinion in Investigational Drugs, 11(2), pp. 126-130

[19] Richter, A. and Wilson T. (2020). Covid-19: implications for insurer risk management and the insurability of pandemic risk. The Geneva Risk and Insurance Review, 45, 171-199

[20] Simpson, A. (2020). Pressure Builds on Insurers to Be Part of Coronavirus Business Solution. Insurance Journal. Retrieved March 20, 2020, from https://www.insurancejournal.com/news/national/2020/03/20/561835.htm

[21] Winters, P. (2020). Swiss Re, Zurich Insurance in Talks with Swiss Regulator About Coronavirus Impact. Insurance Journal. Retrieved March 20, 2020 from https://www.insurancejournal.com/news/international/2020/03/20/561840.hm 